\title{
Analytical Strategies for the Determination of Arsenic in Rice
}

\author{
Bruno E. S. Costa, ${ }^{1}$ Luciana M. Coelho, ${ }^{2}$ Cleide S. T. Araújo, ${ }^{3}$ \\ Helen C. Rezende, ${ }^{4}$ and Nívia M. M. Coelho' ${ }^{1}$ \\ ${ }^{1}$ Institute of Chemistry, Federal University of Uberlândia, Avenida João Naves de Ávila 2121, 38400-902 Uberlândia, MG, Brazil \\ ${ }^{2}$ Department of Chemistry, Federal University of Goiás, Avenida Dr. Lamartine Pinto de Avelar 1120, 75704-020 Catalão, GO, Brazil \\ ${ }^{3}$ State University of Goiás, BR 153, No. 3105, 75132-400 Anápolis, GO, Brazil \\ ${ }^{4}$ Department of Chemistry, Federal University of Goiás, BR 364, km 195, No. 3800, 75801-615 Jataí, GO, Brazil
}

Correspondence should be addressed to Nívia M. M. Coelho; nmmcoelho@ufu.br

Received 25 October 2015; Revised 16 February 2016; Accepted 18 February 2016

Academic Editor: Kamlesh Shrivas

Copyright (C) 2016 Bruno E. S. Costa et al. This is an open access article distributed under the Creative Commons Attribution License, which permits unrestricted use, distribution, and reproduction in any medium, provided the original work is properly cited.

\begin{abstract}
Arsenic is an element of concern given its toxicological significance, even at low concentrations. Food is a potential route of exposure to inorganic arsenic and in this regard arsenic in rice is associated with soil contamination, fertilizer application, and the use of arsenic-containing irrigation water. Therefore, there is a need to investigate the regional rice crops with a view to future discussions on the need for possible regulatory measures. Several studies have reported high concentrations of arsenic in rice grown in soils irrigated with contaminated water; however, procedures used, including sample pretreatment and preconcentration steps, have to be followed to ensure sensitivity, accuracy, and reproducibility. Arsenic is a difficult element to measure in complex matrices, such as foods, because the matrix must be destroyed at an elevated temperature without the loss of the analyte or contamination. This review summarizes the major methods for the determination of arsenic in rice samples. The main purpose of this review is to provide an update on the recent literature concerning the strategies for the determination of arsenic and to critically discuss their advantages and weaknesses. These difficulties are described along with recent developments aimed at overcoming these potential issues.
\end{abstract}

\section{Introduction}

Arsenic (As) is considered to be one of the most important toxic elements because of its potential risk to human health [1]. It is carcinogenic, the inorganic form being the most harmful, and thus it merits particular attention [2-4].

Sources of arsenic in the environment can be natural or anthropogenic, since this element occurs in trace amounts in most rocks as well as in soil, water, and atmospheric dust. Once released into the environment, arsenic compounds reach water sources, such as rivers and groundwater systems, and subsequently food sources. Arsenic-contaminated soil, sediment, and sludge are the major sources of arsenic in the food chain, surface water, groundwater, and drinking water [5]. Arsenic concentrations in noncontaminated soils are typically below $10 \mathrm{mg} / \mathrm{kg}$ while in contaminated soils they can be as high as $30,000 \mathrm{mg} / \mathrm{kg}[6]$.
In the soil environment, arsenic is present mostly as the inorganic species (arsenate $\mathrm{As}(\mathrm{V})$ and arsenite $\mathrm{As}(\mathrm{III})$ ). Inorganic arsenic species can be methylated through microbial action to give monomethylarsonic acid (MMA) and dimethylarsinic acid (DMA). Organic and inorganic arsenic species are present in the solution phase of paddy soils and can also be assimilated by plant roots [7]. Under oxidized condition, since $\mathrm{As}(\mathrm{V})$ is the predominant form (the lesser toxic form in iAs) and can easily be sequestrated by iron oxyhydroxide, it acts as a favorable process limiting arsenic accumulation during rice cultivation [8]. On the other hand, under highly reduced conditions, $\mathrm{As}(\mathrm{V})$ is reduced to $\mathrm{As}(\mathrm{III})$, which precipitates out from the solution in sulfur minerals, primarily arsenopyrite. In paddy soils, due to flooding type irrigation, anoxic condition is generated which favors the release of arsenic from soils and sediments and thereby increases the bioavailability to rice plants. Arsenic can be found as a contaminant in drinking water and foods in the form of different 
chemical species and this affects the assimilation pathway. Recently, published studies about the arsenic content of different food products (including drinking water), indexed in the ISI Web of Science for the period of 2010 to 2015, show that almost $32 \%$ of the papers on arsenic contamination via the diet relate to research on fish samples, while around $29 \%$ are associated with drinking water and $39 \%$ with other food samples, such as rice (which accounts for $52 \%$ of this category). Other foods researched were various cereals and vegetables, edible oils, wine, and beer.

Rice (Oryza sativa) is the most important grain crop worldwide, being consumed by half of the world's population. Studies indicate that rice is a major contributor of inorganic arsenic in human diets [9-16]. Although seafood is known to contain high levels of total arsenic, most of it is present as organic arsenic.

The use of arsenic-containing irrigation water can lead to both long-term soil contamination with arsenic and a supply of arsenic to the crop. Rice accumulates a higher amount of arsenic than any other grain crops, largely because of the high availability of arsenic to plants under reduced soil conditions [17]. Arsenic accumulates in different parts of the rice plants and the accumulation rate varies according to the variety. In one study, arsenic concentrations in rice plant parts were found to decrease in the following order: root $>$ straw $>$ husk $>$ whole grain $>$ husked rice [18]. A higher arsenic accumulation in the roots than in other parts of the plant has also been reported by other authors $[19,20]$. Some authors have observed the translocation of arsenic in plant systems $[21,22]$. The relatively high levels of arsenic in rice are due to several factors including (1) the mobilization and bioavailability of arsenic in the soil after the farmers flood the rice fields and (2) plant uptake of arsenic instead of silicon, which is used by the plant under normal conditions to strengthen the stems and husks. Arsenic and silicon are chemically similar under the soil conditions found in flooded rice paddies and thus arsenic can be transported by the silicon transporters. As the rice plant grows, the plant incorporates arsenic (instead of silicon) into the grain.

Reported levels of As in rice [23-27] are <0.01$2.05 \mathrm{mg} \mathrm{kg}^{-1}$ for Bangladesh, $0.31-0.70 \mathrm{mg} \mathrm{kg}^{-1}$ for China, $0.03-0.044 \mathrm{mg} \mathrm{kg}^{-1}$ for India, $<0.10-0.76 \mathrm{mg} \mathrm{kg}^{-1}$ for Taiwan, $0.11-0.66 \mathrm{mg} \mathrm{kg}^{-1}$ for the US, $0.03-0.47 \mathrm{mg} \mathrm{kg}^{-1}$ for Vietnam, and $0.08-0.38 \mathrm{mg} \mathrm{kg}^{-1}$ for Italy and Spain.

A survey of the research focused on regions with high levels of arsenic contamination in rice within the period covered by this review (2010-2015) returned 335 articles. The main aspects of this survey are highlighted in Figure 1. Most studies relate to the USA and Bangladesh while the other regions are China, the Indian state of West Bengal, India (as a whole), Mexico, Colombia, and Brazil.

According to $\mathrm{WHO}$, the main sources of human exposure to arsenic are water and food [23]. Inorganic arsenic in water is regulated [24, 25]; however, there is no European Union (EU) or United States of America (USA) standard for inorganic arsenic in food products, despite the fact that food products represent the main route of exposure, especially rice and rice-based products $[26,27]$. Recently, the JECFA

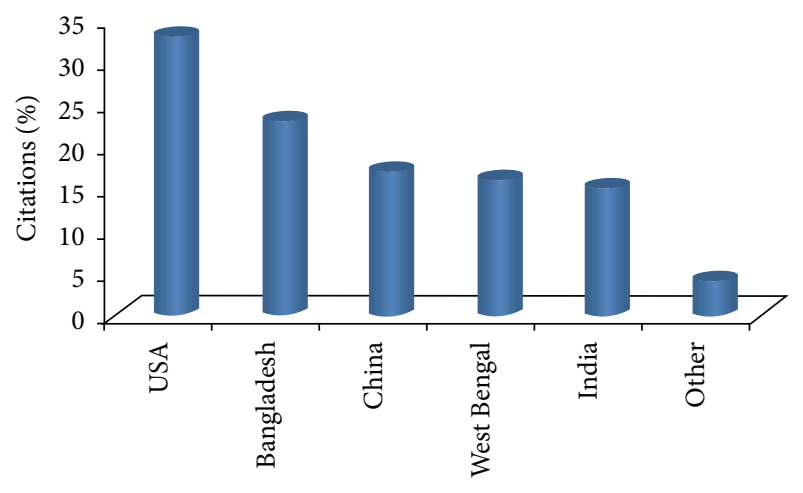

FIGURE 1: Regions with high levels of arsenic contamination in rice.

proposed a maximum level of $0.2 \mathrm{mg} / \mathrm{kg}$ of inorganic arsenic in polished rice [28]. The European Food Safety Authority (EFSA) has reviewed the diet of the European Union population and has recommended that dietary exposure to inorganic arsenic should be reduced. The JECFA also carried out a review and stated that dietary exposure to inorganic arsenic is worthy of considerable attention and should be reduced. Therefore, there is a need to investigate the regional rice crops with a view to future discussions on the need for possible regulatory measures.

Several studies have reported high concentrations of arsenic in rice grown in soils irrigated with contaminated water [29-33]; however, procedures used, including sample pretreatment and preconcentration steps, have to be followed to ensure sensitivity, accuracy, and reproducibility.

Arsenic is a difficult element to measure in complex matrices, such as foods, because the matrix must be destroyed at an elevated temperature without the loss of the analyte or contamination. Determination of As species is generally carried out using hydride-generation ( $\mathrm{HG})[34,35]$, liquid chromatography (LC) [36, 37], gas chromatography (GC) [38], and capillary electrophoresis (CE) $[39,40]$. As speciation, particularly in solid samples, requires very careful sample preparation since this element is volatile, and it is important to avoid modification of the form and concentration of the species [41].

This review summarizes the major methods for the determination of arsenic in rice samples. The main purpose of this review is to provide an update on the recent literature concerning the strategies for the determination of arsenic and to critically discuss their advantages and weaknesses compared with the commonly accepted approach of combining nonchromatographic and spectroscopic techniques. The problems focused on involve sample preparation, as well as changes in "species information" that occur during the use of various separation technologies. These difficulties are described along with recent developments aimed at overcoming these potential issues.

\section{Analytical Methodology}

Analytical procedures for sample preparation are one of the most important steps in analytical methods. At this stage, 
TABLE 1: Sample preparation methods for determination of inorganic arsenic in rice.

\begin{tabular}{|c|c|c|c|c|}
\hline Arsenic species & Sample preparation & Arsenic found $\left(\mathrm{mg} \mathrm{Kg}^{-1}\right)$ & Detection & Reference \\
\hline As total & Hot plate $\left(\mathrm{HNO}_{3}\right)$ & - & ICP-MS & {$[44]$} \\
\hline As total & Microwave digestion $\left(\mathrm{HNO}_{3} / \mathrm{H}_{2} \mathrm{O}_{2}\right)$ & $0.046-0.315$ & ICP-MS & {$[45]$} \\
\hline As inorganic & Microwave digestion $\left(\mathrm{HNO}_{3}\right)$ & $0.029-0.121$ & HPLC-ICP-MS & \\
\hline As total & Ultraclave microwave (trifluoroacetic acid/ $\mathrm{H}_{2} \mathrm{O}_{2}$ ) & $0.036-0.218$ & HPLC-ICPMS & {$[46]$} \\
\hline As inorganic & & $0.025-0.171$ & & \\
\hline As total & - & $0.110-0.421$ & INAA & {$[47]$} \\
\hline As inorganic & Hot plate (water) & $0.050-0.172$ & LC-ICP-MS & \\
\hline As total & Microwave digestion $\left(\mathrm{HNO}_{3} / \mathrm{H}_{2} \mathrm{O}_{2}\right)$ & $0.07-0.47$ & ICP-MS & {$[48]$} \\
\hline As inorganic & Microwave digestion $\left(\mathrm{HNO}_{3}\right)$ & $0.001-0.17$ & HPLC-ICP-MS & \\
\hline As total & Microwave digestion $\left(\mathrm{HNO}_{3}\right.$ concentrated $)$ & $<0.022-0.271$ & ETAAS & {$[49]$} \\
\hline As inorganic & Vortexed and ultrasound $\left(\mathrm{HNO}_{3}\right.$ solution) & $<0.030-0.147$ & & \\
\hline As(III) & Microwave digestion $\left(\mathrm{HNO}_{3}\right.$ solution $)$ & $<0.019-0.097$ & & \\
\hline $\operatorname{As}(\mathrm{V})$ & - & $<0.030-0.076$ & & \\
\hline As total & Hot plate $\left(\mathrm{HNO}_{3}\right)$ & $0.012-0.578$ & ICP-MS & {$[50]$} \\
\hline As total & Ultrasound $\left(\mathrm{HNO}_{3}\right)$ & $0.0125-0.1893$ & ETAAS & [51] \\
\hline $\operatorname{As}(\mathrm{V})$ & & $0.0433-0.0625$ & & \\
\hline As total & Microwave digestion $\left(\mathrm{HNO}_{3} / \mathrm{H}_{2} \mathrm{O}_{2}\right)$ & $0.026-0.464$ & ICP-MS & {$[52]$} \\
\hline As total & Water bath $\left(\mathrm{HNO}_{3}\right.$ solution $)$ & $0.199-0.284$ & HPLC-ICP-MS & [53] \\
\hline As inorganic & - & $0.02-0.18$ & LC-AFS & {$[54]$} \\
\hline As inorganic & Microwave digestion $\left(\mathrm{HNO}_{3} / \mathrm{H}_{2} \mathrm{O}_{2}\right)$ & $0.045-0.235$ & HG-AFS & [55] \\
\hline As total & Microwave digestion & $0.013-0.150$ & HPLC-ICP-MS & {$[56]$} \\
\hline As(III) & ELL (methanol-water $\left.(1: 1) / \mathrm{HNO}_{3}\right)$ & $0.0036-0.0311$ & & \\
\hline $\operatorname{As}(V)$ & & N.D-0.054 & & \\
\hline
\end{tabular}

several variables must be controlled and studied to ensure the quality and reliability of the results. In addition, the determination of arsenic and its species requires very careful sample preparation, since this element is volatile, and it is important to avoid the modification of the chemical form in order to maintain the integrity and concentration of the species of interest during the sample preparation process $[42,43]$.

Some recent studies reported in the literature in which total arsenic and/or inorganic arsenic species were determined are listed in Table 1 and also detailed in the text.

Dwivedi et al. [44] evaluated the effect of the presence of arsenic on the synthesis of essential and nonessential amino acids in rice grains. Rice seeds were obtained and grown with the cooperation of the Rice Research Station, Chinsurah, West Bengal, India, in a randomized block design, following conventional agronomic practices. Sixteen rice genotypes were selected, based on the overall contrast of the grains, from 90 rice germplasms grown in three As-contaminated areas of West Bengal. All field sites were fertilized with chemical fertilizers (N, P, and $\mathrm{K}$ ) and a field trial was conducted over two years. The rice grain samples were pulverized and $0.5 \mathrm{~g}$ was digested in $3 \mathrm{~mL}$ of $\mathrm{HNO}_{3}$ at $100^{\circ} \mathrm{C}$ for $2 \mathrm{~h}$ and $120^{\circ} \mathrm{C}$ for $4 \mathrm{~h}$, then filtered in $10 \mathrm{~mL}$ of water, and stored at $4^{\circ} \mathrm{C}$ until the analysis. The total As in the grain samples was quantified using inductively coupled plasma-mass spectrometer (ICPMS) while the As species were determined according to the protocol described by Zheng et al. [57]. The results of the field tests indicated that the accumulation of As in the soil led to its significant uptake by the rice grains and inhibited the synthesis of amino acids in some genotypes [44].

Carbonell-Barrachina et al. [45] analyzed Spanish rice gluten, cereals with gluten, and baby food and determined the total arsenic ( $\mathrm{t}-\mathrm{As}$ ) and inorganic arsenic ( $\mathrm{i}-\mathrm{As}$ ) using ICP-MS and high performance liquid chromatography (HPLC) with ICP-MS (HPLC-ICP-MS), respectively. Samples were dried in an oven at $80^{\circ} \mathrm{C}$ until constant weight and then homogenized by grinding in a ball mill and stored in a desiccator. For the determination of total arsenic, $0.2 \mathrm{~g}$ of dried product was placed overnight in contact with $2 \mathrm{~mL}$ of concentrated nitric acid. The samples were then digested in a microwave oven with hydrogen peroxide applying a temperature program reaching a maximum of $95^{\circ} \mathrm{C}$. A certified reference material (CRM; rice flour NIST SRM 1568a) was used to assess the precision and accuracy of the chemical analysis. Arsenic species were extracted according to conditions previously described for t-As. However, $\mathrm{HNO}_{3}(1 \%(\mathrm{w} / \mathrm{v}))$ was used and the microwave digestion was conducted without the addition of hydrogen peroxide. The digested samples were centrifuged and $900 \mu \mathrm{L}$ of the filtered supernatant was mixed with $100 \mu \mathrm{L}$ of $\mathrm{H}_{2} \mathrm{O}_{2}$ and left overnight at $4^{\circ} \mathrm{C}$. The content of inorganic arsenic was significantly higher in the Spanish rice gluten than in the cereals with gluten, placing children with celiac disease at high risk, since rice gluten is used as a replacement in gluten-free food products (note that rice gluten differs from "true gluten").

Raber et al. [46] proposed an analytical method for quantitatively determining inorganic arsenic in foods (including 
rice). Rice samples were ground in a centrifugal mill to a particle size of $<0.25 \mathrm{~mm}$. The authors studied different sample preparation methods to improve the extraction efficiency and the compatibility between the extract and the chromatographic separation method. Among the different extractors studied, trifluoroacetic acid was found to be a potential reagent for the extraction of inorganic arsenic (iAs) from rice and no change in the retention time compared with aqueous standard solutions was noted. In the sample preparation procedure a portion of the powdered samples was placed in a quartz tube, to which $5 \mathrm{~mL}$ of $0.02 \mathrm{~mol} \mathrm{~L}^{-1}$ trifluoroacetic acid containing $50 \mu \mathrm{L}$ of a $30 \% \mathrm{H}_{2} \mathrm{O}_{2}$ solution was added and the suspension was sonicated for $15 \mathrm{~min}$. The tubes were transferred to a Teflon rack of the Ultraclave microwave system which was closed. An argon pressure of $4 \cdot 10^{6} \mathrm{~Pa}$ was then applied and the mixture was heated to $95^{\circ} \mathrm{C}$ over a period of $10 \mathrm{~min}$ and this temperature was maintained for $60 \mathrm{~min}$. After cooling to room temperature $1 \mathrm{~mL}$ aliquots of the extracts were transferred to vials and centrifuged. The supernatant was used directly for the HPLC-ICP-MS analysis.

According to Sun et al. [58], rice can easily accumulate As and the bioavailability of As released from this food matrix was assessed using an in vitro gastrointestinal simulator. Water, monosodium arsenate $\left(\mathrm{NaH}_{2} \mathrm{AsO}_{4}\right)$, and sodium arsenite $\left(\mathrm{NaAsO}_{2}\right)$ were used and the samples were taken from the stomach, intestines, and colon. The analysis was carried out by ICP-MS and speciation was performed by HPLC. Procedures such as rice washing and cooking did not affect the result of the rice speciation although the arsenic content decreased in the range of 7.1 to $20.6 \%$.

Brockman and Brown IV [47] extracted arsenic species from infant rice cereals through a hot water extraction procedure. Deionized water was added to each tube and the samples were maintained at $98^{\circ} \mathrm{C}$ (using a hot block) for $3 \mathrm{~h}$. After cooling to room temperature the samples were centrifuged for $1 \mathrm{~h}$ in a centrifuge filtration system. The resultant filtered extract was diluted 1:25 with eluent and $100 \mu \mathrm{L}$ of $30 \%$ hydrogen peroxide to oxidize the arsenite. Rice samples were analyzed for total arsenic by instrumental neutron activation analysis (INAA) and inorganic arsenic by liquid chromatography (LC) with ICP-MS (LC-ICP-MS).

The variability observed among rice grains is another dietary research approach to assessing arsenic exposure. Sommella et al. [48] evaluated the total arsenic and iAs in Italian rice grains and found that they varied by geographic origin and type. Concentrated $\mathrm{HNO}_{3}(2.5 \mathrm{~mL})$ was added to the pulverized samples and the mixture was left overnight. In the next step, $\mathrm{H}_{2} \mathrm{O}_{2}$ was added and the samples were digested in a microwave oven with a specific program. The samples were then cooled to room temperature and diluted to $50 \mathrm{~mL}$ with ultrapure deionized water. In the extraction procedure to investigate the speciation, $10 \mathrm{~mL}$ of $1 \%(\mathrm{w} / \mathrm{v}) \mathrm{HNO}_{3}$ was used and the same microwave temperature program applied to determine the total arsenic was employed. At room temperature, the samples were centrifuged and $900 \mu \mathrm{L}$ of supernatant was mixed with $100 \mu \mathrm{L}$ of $\mathrm{H}_{2} \mathrm{O}_{2}$. The samples were left overnight at $4^{\circ} \mathrm{C}$ before analysis. Inorganic arsenic was quantified by HPLC coupled to ICP-MS.
Pasias et al. [49] developed three different methods for the determination of total arsenic, total inorganic arsenic, and $\mathrm{As}(\mathrm{III})-\mathrm{As}(\mathrm{V})$ in rice and rice flour food products. For the determination of total arsenic, $0.5 \mathrm{~g}$ of the homogenized rice or rice flour samples was digested in a microwave oven with $5 \mathrm{~mL}$ of concentrated $\mathrm{HNO}_{3}$. For the determination of inorganic arsenic, $0.5 \mathrm{~g}$ of sample and $5 \mathrm{~mL}$ of $1 \mathrm{~mol} \mathrm{~L}^{-1}$ $\mathrm{HNO}_{3}$ were vortexed and ultrasonicated for $15 \mathrm{~min}$ and then centrifuged at $4000 \mathrm{rpm}$ for $15 \mathrm{~min}$. In the next step $15 \mathrm{~mL}$ of $0.1 \%(\mathrm{w} / \mathrm{v})$ EDTA was added to the mixture which was then vortexed again and centrifuged at $4000 \mathrm{rpm}$ for $15 \mathrm{~min}$. The supernatant was analyzed by ETAAS. Finally, for the determination of $\mathrm{As}(\mathrm{III})$ and $\mathrm{As}(\mathrm{V}), 0.5 \mathrm{~g}$ of the sample was digested in a microwave oven with $5 \mathrm{~mL}$ of $1 \mathrm{~mol} \mathrm{~L}^{-1}$ $\mathrm{HNO}_{3}$ (the highest temperature reached was only $85^{\circ} \mathrm{C}$ ), and the extract was treated with $5 \mathrm{~mL} 5 \%$ EDTA (w/v). As(III) was determined and $\mathrm{As}(\mathrm{V})$ was then determined from the difference between the total inorganic As and As(III).

Phan et al. [50] investigated the potential exposure of Cambodian villagers to arsenic from their daily food consumption. Samples of lowland soils, paddy rice (raw and cooked), fish, and vegetables were collected from the Kandal, Kratie, and Kampong Cham provinces in the Mekong River basin in Cambodia. After acid digestion, extracts were analyzed by ICP-MS. The results revealed that the total concentrations of arsenic in lowland soils and paddy rice were significant. The samples were treated with concentrated $\mathrm{HNO}_{3}(65 \%)$, the mixture was heated to $96^{\circ} \mathrm{C}$ and maintained at this temperature for one hour, and after cooling $5 \mathrm{~mL}$ of water was added. The extract was centrifuged and filtered and then the total arsenic was quantified by ICP-MS.

An interesting approach to determining total arsenic and $\mathrm{As}(\mathrm{V})$ with detection by electrothermal atomic absorption spectrometry after cloud point extraction (ETAAS/CPE), using ultrasound for the sample preparation, was developed by Costa et al. [51]. This procedure is based on the formation of a complex of $\mathrm{As}(\mathrm{V})$ ions with molybdate in the presence of sulfuric acid and extraction into the surfactant-rich phase with Triton X-114. The powdered samples were sonicated for 136 min with a $0.5 \mathrm{~mol} \mathrm{~L}^{-1}$ solution of nitric acid. For the $\mathrm{As}(\mathrm{V})$ determination an aliquot of the extract was submitted to the CPE methodology and for the total As determination an aliquot of the extract passed through a prereduction step with $1.0 \mathrm{~mL}$ of $8 \times 10^{-8} \mathrm{~mol} \mathrm{~L}^{-1} \mathrm{KMnO}_{4}$ and agitation for 30 min was applied before the CPE methodology.

Shraim [52] evaluated the presence of various metals including arsenic in rice sold in Saudi Arabia. The sample preparation consisted of the microwave digestion of samples that were previously milled using an analytical hand mill. Digestion was carried out applying a specific temperature program and the digestion agents used were concentrated nitric acid, water, and hydrogen peroxide. After the solutions had been digested they were diluted with water and a portion was filtered and analyzed by ICP-MS.

A method for the determination of total arsenic and inorganic arsenic in rice using HPLC-ICP-MS has been developed. Prior to analysis the samples are treated with $0.28 \mathrm{~mol} \mathrm{~L}^{-1} \mathrm{HNO}_{3}$ and heated in a water bath $\left(95^{\circ} \mathrm{C}\right)$ for 
$90 \mathrm{~min}$. After cooling to room temperature, the extracts were centrifuged at $5000 \mathrm{rpm}$ for $35 \mathrm{~min}$ at $18^{\circ} \mathrm{C}$, filtered, and analyzed [53].

In order to relate the inorganic arsenic (iAs) content in the rice to the As present in the soil, considering properties such as $\mathrm{pH}$, TOC, available $\mathrm{P}$, and available Fe, rice and soil samples were collected in a region of south China (with a typical red soil for which arsenic contamination has not been reported) and analyzed. The rice grain samples were washed with deionized water, air dried at room temperature, and ground into fine particles. The inorganic As in the grains was determined by liquid chromatography-atomic fluorescence spectrometry (LC-AFS). The results showed that the soil $\mathrm{pH}$ and available phosphorus were the main factors influencing the uptake of As by rice grains. The presence of phosphorus suppresses As uptake by rice grains and competition between arsenic and phosphorus for transporters affects the transport from the soil to the roots in the rhizosphere [54].

G. Chen and T. Chen [55] carried out a study focused on iAs in rice samples. The samples were processed to a fine powder using a small mill. A microwave reaction system (rated at $1200 \mathrm{~W}$ ) was used $\left(95^{\circ} \mathrm{C}\right.$ for $30 \mathrm{~min}$ ) with an extraction solution comprised of $0.06 \mathrm{~mol} \mathrm{~L}^{-1} \mathrm{HNO}_{3}$ and $3 \%(\mathrm{w} / \mathrm{v}) \mathrm{H}_{2} \mathrm{O}_{2}$. After cooling, the solutions were transferred to centrifuge tubes and centrifuged for $15 \mathrm{~min}$ at room temperature. During digestion, As(III) was oxidized to As(V) and silica-based strong anion exchange cartridges were used to separate the As $(\mathrm{V})$ from organic As forms. Inorganic As was quantified by hydride-generation atomic fluorescence spectrometry (HG-AFS) after prereduction by iodide [55].

A simple procedure for the extraction of As species from polished rice samples has been described. For arsenic species determination, sample was ground to a fine powder in a homogenizer and $1 \mathrm{~g}$ was mixed with $10 \mathrm{~mL}$ of a methanolwater $(1: 1)$ mixture containing $1 \% \mathrm{HNO}_{3}$ in a centrifuge tube and the mixture was sonicated for $30 \mathrm{~min}$. The extracts were centrifuged and stored at $-4^{\circ} \mathrm{C}$ prior to analysis. As species were previously separated by HPLC and measured by ICP-MS [56]. Total arsenic was extracted in a microwave oven with $9 \mathrm{~mL}$ of $70 \%$ nitric acid and $1 \mathrm{~mL}$ of hydrogen peroxide and after the digestion the extracts were diluted with water. The total content of As was measured by ICP-MS [56].

Extraction methods involve the selective separation of a target species from its matrix (e.g., rice). The methodology employed should ensure quantitative and reproducible extraction without altering the species pattern by decomposition, chemical conversion, or insufficient extraction yield. This is especially important due to the complexity of rice sample matrices. In this context, conventional extraction, also known as heating by hot plate, is one of the traditional methods most widely used for sample treatment. Based on this sample preparation strategy, several approaches have been used for arsenic extraction from acidic samples [44, $47,50]$. The concentrated acids are the most used extractant. Water is the extractant most commonly recommended for the more polar or ionic species of arsenic, but few studies are reported in the literature regarding the extraction of these species from water due to the low yields obtained.
In contrast with conventional extraction methods, for example, liquid-liquid extraction (LLE), which are characterized by the use of high volumes of solvents and long extraction times [56], the use of microwave energy results in a significant reduction in the extraction time, because the microwaves accelerate the heating rate $[45,46,48,49,52$, $54,55]$. Other advantages of microwave-assisted extraction are high recoveries, good reproducibility, and minimal sample manipulation. The most critical parameters for method optimization using microwave extraction procedures are the extraction medium, applied microwave power, and extraction time [34]. Most of microwave extraction procedures involve the use of nitric acid [46,59-61]. Nitric acid is a strong oxidizing agent; however, its use in digestion procedures constitutes an important source of interference due to the formation of nitrogen oxides.

Many factors are important in the process of sample preparation, such as the physical state of the sample, the analyte that is determined, and the type of detection. In general, the analysis of solid samples such as rice is more difficult since most detection methods require that the analytes of interest are transferred to a liquid phase. In this context the ultrasound-assisted extraction of the analyte emerged as an efficient alternative which requires a short time and the use of acids in low concentration and operation conditions involving atmospheric pressure and room temperature $[51,62,63]$. The use of ultrasound involves the solidliquid extraction. Sonication by ultrasound occurs in the acoustic cavitation process resulting in points with extremely high temperature and pressure gradients. This phenomenon occurs near the particle surface or in the surface itself and improves the analyte solubility and diffusivity of solvent inside the solid particles. The chemical effect of ultrasound improves the reactivity of some chemicals, allowing the occurrence and also acceleration of some reactions involved in sample digestion.

\section{Arsenic Speciation}

Rice is a crop plant which can absorb more arsenic than other cereals, such as barley and wheat, as shown in a study by Meharg and Rahman [64]. Thus, it is important to monitor the contamination of rice with arsenic and in order to estimate the risk to human health variations in the toxicity, mobility and bioavailability, factors which are strongly dependent on the chemical form in which the arsenic is present, must be taken into account.

For the effective diagnosis of the degree of toxicity through contamination by inorganic species of arsenic in rice, it is necessary to develop analytical methodologies to aid the differentiation of these forms. Separation and detection techniques can be used to study the chemical speciation; however, the majority of these techniques are limited because they do not tend to combine an efficient separation capacity with the sensitivity and selectivity required for detection. Hyphenated chromatographic methods, such as HPLC-ICPMS, have become the preferred and most commonly used approach for this purpose. The main advantages are the high 
TABLE 2: Speciation of arsenic in rice using HPLC-ICP-MS.

\begin{tabular}{|c|c|c|c|}
\hline Arsenic species & Sample preparation & Figures of merit & Reference \\
\hline $\begin{array}{l}\text { As(III), As(V), DMA, } \\
\text { MMA, AsC, and AsB }\end{array}$ & Microwave digestion with $1 \%(\mathrm{v} / \mathrm{v}) \mathrm{HNO}_{3}$ & $\begin{array}{c}\text { LOD: } 0.1-0.3 \mu \mathrm{g} / \mathrm{Kg} \\
\text { LOQ: } 0.5-1.5 \mu \mathrm{g} / \mathrm{Kg} \\
\text { Recovery: } 91.4-114.3 \%\end{array}$ & {$[59]$} \\
\hline $\begin{array}{l}\text { Total As, As(III), As(V), } \\
\text { DMA, MMA, and AsB }\end{array}$ & Pressurized liquid extraction sonication & Recovery: $71.8-104.5 \%$ & {$[62]$} \\
\hline $\begin{array}{l}\text { As(III), As(V), DMA, and } \\
\text { MMA }\end{array}$ & $\begin{array}{l}\text { Microwave digestion with } 10 \mathrm{~mL} \text { of } \\
\qquad 2 \%(\mathrm{v} / \mathrm{v}) \mathrm{HNO}_{3}\end{array}$ & LOD: $0.03 \mu \mathrm{g} / \mathrm{L}$ for total As & {$[60]$} \\
\hline $\begin{array}{l}\text { As(III), As(V), MMA, and } \\
\text { DMA }\end{array}$ & Sonication by ultrasound probe & $\begin{array}{l}\text { LOD: } 0.05-0.2 \mu \mathrm{g} / \mathrm{Kg} \\
\text { Recovery: } 82-99 \%\end{array}$ & [63] \\
\hline $\begin{array}{l}\text { As(III), As(V), MMA, and } \\
\text { DMA }\end{array}$ & Extraction with $1 \% \mathrm{HNO}_{3}$ & $\begin{array}{l}\text { LOD: } 0.01-0.07 \mu \mathrm{g} / \mathrm{L} \\
\text { Recovery: } 95-100 \%\end{array}$ & {$[61]$} \\
\hline $\begin{array}{l}\text { MMA, DMA, As(III), and } \\
\operatorname{As}(\mathrm{V})\end{array}$ & $\begin{array}{l}\text { Digestion of the samples using } \\
\text { pressurized microwave system }\end{array}$ & $\begin{array}{l}\text { LOD: } 0.5-1.0 \mu \mathrm{g} / \mathrm{Kg} \\
\text { Recovery: } 94-98 \%\end{array}$ & {$[46]$} \\
\hline
\end{tabular}

LOD: limit of detection; LOQ: limit of quantification.

sensitivity, multielement capacity, wide linear range, and possibility for isotope determination.

Studies reported in the literature in which arsenic species were determined mainly by HPLC-ICP-MS are listed in Table 2.

Kim et al. [59] determined As(III), As(V), DMA, MMA, $\mathrm{AsB}$, and $\mathrm{AsC}$ in rice grains in samples grown in Korea and USA using HPLC-ICP-MS. As(III) was the species predominantly found in the samples. The results indicated high toxic effect and need for further attention.

Sanz et al. [62] held arsenic speciation analysis in samples of rice, straw, soil, hair, and nail in regions affected by arsenic contamination in the eastern and western plains of the Ganga down and Bangladesh. Arsenic species (As(III), As(V), DMA, MMA, and AsB) were determined by HPLC-ICP-MS. For the samples of rice, the content of inorganic arsenic corresponds to $70-98 \%$ of the total arsenic content (up to $636.7 \mathrm{mg} / \mathrm{kg}$ in the samples). The authors indicate that the speciation analysis reveals itself as a powerful tool for full analytical assessment in epidemiological studies.

Maher et al. [60] determined As(III), As(V), DMA, and MMA in rice varieties from Australia. Total arsenic was determined by electrothermal atomic absorption spectrometry (ETAAS) after extraction with concentrated nitric acid. Inorganic arsenic and methylated species were determined by HPLC-ICP-MS. The method was validated by comparing the results with $\mathrm{X}$-ray absorption near edge spectroscopy (XANES). The determination by XANES allows direct analysis, dispensing steps prior extraction and preventing problems from changes in arsenic species [60].

Sanz et al. [63] studied a procedure for the extraction of As(III), As(V), MMA, and DMA in rice samples from Spain and India. The speciation was also performed by HPLC-ICP-MS. The total arsenic was determined by ICPMS after digestion of the rice samples with hydrogen peroxide and concentrated nitric acid assisted by microwave. For speciation analysis, the extraction of arsenic species occurred through the enzymatic action of $\alpha$-amylase and ultrasonic probe sonication in a short period of time ( $3 \mathrm{~min})$.
The extraction procedure has shown more efficiency than conventional methods, avoiding the use of highly dangerous organic solvents. As(III) was predominantly the arsenic form found in rice samples analyzed. These results show that rice is a bioaccumulative plant for the more toxic form of arsenic.

Sun et al. [61] performed an arsenic speciation study on products derived from rice, such as cereals commonly eaten at breakfast, rice crackers, and condiments used to prepare Japanese rice. Arsenic species (As(III), As(V), MMA, and DMA) were extracted from samples with $1 \%(\mathrm{v} / \mathrm{v}) \mathrm{HNO}_{3}$ and quantified by HPLC-ICP-MS. The inorganic forms were prevalent (75.2 to $90.1 \%)$. The study provided useful information which leads to a better understanding of the distribution of arsenic species in rice products. These are important considerations in the formulation of new rice-based foods.

Hyphenated chromatographic methods contribute significantly to enhancing the study of arsenic speciation, but they are still costly and thus the development of nonchromatographic methods is a more accessible and promising approach. A major challenge in speciation analysis is to maintain the integrity of the chemical species of interest from the sampling to the detection stages. In nonchromatographic methods, selective extraction procedures using a small volume of extractor are often required, based on the analyte partitioning into a phase with compatible polarity. This type of extraction procedure has the advantage of preconcentration and the minimization of matrix effects. However, if the partitioning is not quantitative, low recoveries can be observed.

Nonchromatographic methods offer several advantages over the chromatographic techniques and represent a fast and inexpensive option for application in laboratories, particularly when applied to food and environmental samples. However, many of these methods provide limited information on the samples since most approaches have centered on a single element or a specific type of chemical form (i.e., free ions or organic compounds).

In addition to the challenge of preventing interconversion of species during the extraction steps, most procedures 
TABLE 3: Nonchromatographic methods for speciation of arsenic in rice.

\begin{tabular}{|c|c|c|c|c|}
\hline Arsenic species & Sample preparation & Detection & Figures of merit & Reference \\
\hline As(III) and As(V) & $\begin{array}{l}\text { Assisted digestion microwave with } \\
0.14 \mathrm{~mol} / \mathrm{L} \mathrm{HNO}_{3}\end{array}$ & HG-AAS & LOD: $1.96-3.85 \mathrm{ng} / \mathrm{g}$ & {$[65]$} \\
\hline $\mathrm{As}(\mathrm{III})$ and $\mathrm{As}(\mathrm{V})$ & $\begin{array}{l}\text { Vortex with } 25 \mathrm{~mL} \text { of solution } \\
0.05 \mathrm{~mol} / \mathrm{L}\left(\mathrm{NH}_{4}\right)_{2} \mathrm{CO}_{3}\end{array}$ & HG-AFS & $\begin{array}{l}\text { LOD: } 1.3-4.4 \mathrm{ng} / \mathrm{g} \\
\text { Recovery: } 94-95 \%\end{array}$ & {$[55]$} \\
\hline As(III) and As(V) & Cloud point extraction & UV-Vis & $\begin{array}{c}\text { LOD: } 1.14 \mu \mathrm{g} / \mathrm{L} \\
\text { Enrichment factor: } 65 \\
\text { Recovery: } 95-102 \%\end{array}$ & {$[66]$} \\
\hline Total As and As(V) & Sonication with $0.5 \mathrm{~mol} / \mathrm{L} \mathrm{HNO}_{3}$ & ETAAS & $\begin{array}{c}\text { LOD: } 10-33 \mathrm{ng} / \mathrm{L} \\
\text { Enrichment factor: } 78.3 \\
\text { Recovery: } 90.8-113.1 \%\end{array}$ & {$[51]$} \\
\hline $\begin{array}{l}\text { Inorganic As, MMA, } \\
\text { DMA, and AsB }\end{array}$ & $\begin{array}{l}0.01 \mathrm{~mol} / \mathrm{L} \text { TMAH } \\
\text { (tetramethylammonium hydroxide) }\end{array}$ & ETAAS & LOD: $15-50 \mathrm{ng} / \mathrm{g}$ & {$[67]$} \\
\hline $\begin{array}{l}\text { Total As, As(III), and } \\
\text { As }(V)\end{array}$ & $\begin{array}{l}\text { Assisted digestion microwave with } \\
1.0 \mathrm{~mol} / \mathrm{L} \mathrm{HNO}_{3}\end{array}$ & ETAAS & $\begin{array}{c}\text { LOD: } 19-30 \mu \mathrm{g} / \mathrm{Kg} \\
\text { LOQ: } 57-90.3 \mu \mathrm{g} / \mathrm{Kg} \\
\text { Recovery: } 92-105 \%\end{array}$ & {$[49]$} \\
\hline
\end{tabular}

LOD: limit of detection; LOQ: limit of quantification.

end up being restricted to inorganic species, and there are few studies using nonchromatographic procedures for determination of organic arsenic species. This challenge makes nonchromatographic speciation procedures more promising, opening an opportunity for research aimed at improving this focus. Table 3 listed some studies reported in the literature using nonchromatographic procedures for arsenic speciation in rice samples.

Speciation is relatively easy to investigate when a property of a particular compound can be measured directly in the sample without interference from the other matrix components. Direct speciation analysis is generally considered to be less challenging although this is not always the case.

Studies on direct and in situ analysis are increasing due to interest in simplifying the process of rapid substance identification for monitoring and quality control in the food industry. There are very few methods available for the determination of the speciation in solid food samples through direct analysis. The use of mass spectrometry (MS), with only a few sample preparation steps, allows the speciation of organic arsenic to be determined, with limited analyte loss. In contrast, matrix-assisted laser desorption/ionization (MALDI), electrospray ionization (ESI), and desorption electrospray ionization (DESI), despite being associated with greater losses, have greater tolerance in the presence of impurities, proving to be valuable for metal complexes [68].

Lin et al. [69] demonstrated that DESI-MS can be used as desorption/ionization technique for the determination of arsenic speciation (inorganic arsenic, monomethyl arsenic acid, dimethylarsinic acid, and arsenobetaine) in biological samples under environmental conditions. The results were effective in the identification of inorganic and organic arsenic compounds. Furthermore, the DESI method does not require sample preparation and its use has proved to be promising for in situ speciation studies [69].

Finally, more recently, the development of speciation techniques has been highly focused on physical methods, such as X-ray diffraction (XRD), X-ray powder diffraction
(XPD), and X-ray absorption spectroscopy (XAS) [70, 71]. However, it is clear that the cost of the instrumentation and the attainable sensitivity are not sufficient for routine speciation analysis of food samples [72]. For speciation, Xray absorption near edge structure (XANES) spectroscopy is a powerful tool, because it is a direct method by which we can avoid the change of the chemical state of target elements. XANES is a nondestructive technique for identifying inorganic and organic arsenic species in complex environmental samples [73].

Manning described a procedure to evaluate the solid phase oxidation state and mineral surface binding sites in three agricultural soil samples by fitting linear combinations of XANES spectra derived from several synthetic and well characterized As(III)- and As(V)-treated model compounds. The data showed that As(III) is either partially or completely oxidized to As(V) when reacting with soil [74].

There is a trend toward reducing the sample preparation steps in order to limit the interconversion of species, providing more accurate results on the quantity of each species in the sample. However, based on this review it is clear that there are still considerable difficulties associated with reducing the number of sample preparation steps involved in speciation studies. Thus, in this regard, many approaches are focused on total arsenic without considering the specific chemical forms (free ions or organic compounds) and the information provided on the samples is consequently very limited. It is expected that procedures for direct speciation studies or a reduction in the number of preparation steps will be developed in the near future, based on the use of MALDI, ESI, DESI-MS, and X-ray, with chromatographic or nonchromatographic detection techniques. This approach could provide the best aspects of screening methods, particularly in relation to reduced handling, and involves the direct characterization of chemical forms, contributing to improving our understanding of the behavior of the different chemical forms of arsenic in food samples such as rice. 


\section{Conclusions}

High levels of arsenic in rice grains are a potential concern in relation to human health. More information on arsenic speciation in rice and rice-based products for consumption is needed in order to carry out risk assessment studies on inorganic arsenic. The largest gap in our knowledge with regard to assessing inorganic arsenic consumption rates from rice is related to the levels of arsenic species in rice and rice products and appropriate analytical methods for speciation of arsenic ensure the integrity of the species.

A comprehensive risk assessment must be based on information on the dietary status and consumption of rice, along with the calculation of the daily intake of arsenic from the various routes of human exposure. The most commonly reported concern is arsenic entering the food chain, affecting food safety. Management options for health risk prevention and agricultural sustainability should therefore focus on minimizing As inputs to soils and limiting human exposure.

This review is not exhaustive, but it highlights some of the important and unique aspects related to the presence of arsenic in rice, addressed within the context of human nutrition. Due to the increasing consumption of rice, the available analytical methods need to be able to provide more detailed information on the chemical species present, overcoming the barrier created by the complexity of food matrices and the low concentrations of the analyte present. Unfortunately, the procedures for arsenic speciation studies are not yet suitable for routine analysis and clearly the development of such methods offers a great challenge for analysts around the world. Thus, the search for simple strategies suitable for obtaining quantitative information regarding arsenic species should be encouraged. However, these strategies require an interdisciplinary approach in order to cover the various aspects involved and represent a considerable challenge in the areas of toxicology and analytical chemistry.

\section{Abbreviations}

As: $\quad$ Arsenic

AsB: Arsenobetaine

AsC: Arsenocholine

As(V): Arsenate

As(III): Arsenite

CE: Capillary electrophoresis

CPE: $\quad$ Cloud point extraction

CRM: Certified reference material

DMA: Dimethylarsinic acid

DESI-MS: Desorption electrospray ionization-mass spectrometry

EDTA: Ethylenediaminetetraacetic acid

EFSA: European Food Safety Authority

ESI-MS: Electrospray-mass spectrometry

ETAAS: Electrothermal atomic absorption spectrometry

EU: $\quad$ European Union

GC: $\quad$ Gas chromatography

HG: Hydride-generation
HG-AFS: Hydride-generation atomic fluorescence spectrometry

HPLC: $\quad$ High performance liquid chromatography

iAs: Inorganic arsenic

INAA: Instrumental neutron activation analysis

ICP-MS: Inductively coupled plasma-mass spectrometer

JECFA: Food and Agriculture Organization/World Health Organization

LC: $\quad$ Liquid chromatography

LC-AFS: Liquid chromatography-atomic fluorescence spectrometry

LC-ICP-MS: Liquid chromatography-inductively

coupled plasma-mass spectrometry

MMA: Monomethylarsonic acid

MS: $\quad$ Mass spectrometry

MALDI: Matrix-assisted laser

desorption/ionization

USA: $\quad$ United States of America

XRD: $\quad$ X-ray diffraction

XPD: $\quad$ X-ray powder diffraction

XAS: $\quad$ X-ray absorption spectroscopy

WHO: $\quad$ World Health Organization.

\section{Competing Interests}

The authors declare that there are no competing interests regarding the publication of this paper.

\section{Acknowledgments}

The authors are grateful for financial support from the Brazilian governmental agencies Conselho Nacional de Desenvolvimento Científico e Tecnológico (CNPq) and Coordenação de Aperfeiçoamento de Pessoal de Nível Superior (CAPES), the MG state government agency Fundação de Amparo à Pesquisa do Estado de Minas Gerais (FAPEMIG), and the GO state government agency Fundação de Amparo á Pesquisa do Estado de Goiás (FAPEG).

\section{References}

[1] R. Naidu, E. Smith, G. Owens, P. Bhattacharya, and P. Nadebaum, Managing Arsenic in the Environment-From Soil to Human Health, CSIRO Publishing, Melbourne, Australia, 2006.

[2] ATSDR (Agency for Toxic Substances and Disease Registry), "Comprehensive Environmental Response, Compensation and Liability Act (CERCLA)," Priority list of hazardous substances. U.S., 2011, http://www.atsdr.cdc.gov/cercla.

[3] M. F. Hughes, B. D. Beck, Y. Chen, A. S. Lewis, and D. J. Thomas, "Arsenic exposure and toxicology: a historical perspective," Toxicological Sciences, vol. 123, no. 2, pp. 305-332, 2011.

[4] C. L. Chen and P. D. Whanger, "Interaction of selenium and arsenic with metallothionein: effect of vitamin B12," Journal of Inorganic Biochemistry, vol. 54, no. 4, pp. 267-276, 1994.

[5] W. J. Frankenberger and M. Arshad, "Volatilisation of arsenic," in Environmental Chemistry of Arsenic, pp. 363-380, Marcel Dekker, New York, NY, USA, 2002. 
[6] M. A. Rauf, M. A. Hakim, M. M. Hanafi, M. M. Islam, G. K. M. M. Rahman, and G. M. Panaullah, "Bioaccumulation of arsenic (As) and phosphorous by transplanting Aman rice in arseniccontaminated clay soils," Australian Journal of Crop Science, vol. 5, no. 12, pp. 1678-1684, 2011.

[7] J. Abedin, M. S. Cresser, A. A. Meharg, J. Feldmann, and J. Cotter-Howells, "Arsenic accumulation and metabolism in rice (Oryza sativa L.)," Environmental Science and Technology, vol. 36, no. 5, pp. 962-968, 2002.

[8] P. L. Smedley and D. G. Kinniburgh, "A review of the source, behaviour and distribution of arsenic in natural waters," Applied Geochemistry, vol. 17, no. 5, pp. 517-568, 2002.

[9] D. M. Meacher, D. B. Menzel, M. D. Dillencourt et al., "Estimation of multimedia inorganic arsenic intake in the US population," Human and Ecological Risk Assessment, vol. 8, no. 7, pp. 1697-1721, 2002.

[10] J. R. Meliker, A. Franzblau, M. J. Slotnick, and J. O. Nriagu, "Major contributors to inorganic arsenic intake in southeastern Michigan," International Journal of Hygiene and Environmental Health, vol. 209, no. 5, pp. 399-411, 2006.

[11] R. A. Schoof, L. J. Yost, J. Eickhoff et al., "A market basket survey of inorganic arsenic in food," Food and Chemical Toxicology, vol. 37, no. 8, pp. 839-846, 1999.

[12] X.-Y. Liao, T.-B. Chen, H. Xie, and Y.-R. Liu, "Soil As contamination and its risk assessment in areas near the industrial districts of Chenzhou City, Southern China," Environment International, vol. 31, no. 6, pp. 791-798, 2005.

[13] P. N. Williams, A. Raab, J. Feldmann, A. A. Meharg, and P. N. Williams, "Market basket survey shows elevated levels of as in south central U.S. Processed rice compared to california: consequences for human dietary exposure," Environmental Science \& Technology, vol. 41, no. 7, pp. 2178-2183, 2007.

[14] L. J. Yost, S.-H. Tao, S. K. Egan et al., "Estimation of dietary intake of inorganic arsenic in US children," Human and Ecological Risk Assessment, vol. 10, no. 3, pp. 473-483, 2004.

[15] P. Bhattacharyya, A. K. Ghosh, A. Chakraborty, K. Chakrabarti, S. Tripathy, and M. A. Powell, "Arsenic uptake by rice and accumulation in soil amended with municipal solid waste compost," Communications in Soil Science and Plant Analysis, vol. 34, no. 19-20, pp. 2779-2790, 2003.

[16] H. Liu, A. Probst, and B. Liao, "Metal contamination of soils and crops affected by the Chenzhou lead/zinc mine spill (Hunan, China)," Science of the Total Environment, vol. 339, no. 1-3, pp. 153-166, 2005.

[17] A. R. Marin, P. H. Masscheleyn, and W. H. Patrick Jr., "Soil redox-pH stability of arsenic species and its influence on arsenic uptake by rice," Plant and Soil, vol. 152, no. 2, pp. 245-253, 1993.

[18] A. R. Marin, P. H. Masscheleyn, and W. H. Patrick Jr., "The influence of chemical form and concentration of arsenic on rice growth and tissue arsenic concentration," Plant and Soil, vol. 139, no. 2, pp. 175-183, 1992.

[19] Z. M. Xie and C. Y. Huang, "Control of arsenic toxicity in rice plants grown on an arsenic-polluted paddy soil," Communications in Soil Science and Plant Analysis, vol. 29, no. 15-16, pp. 2471-2477, 1998.

[20] Y. Odanaka, N. Tsuchiiya, O. Matano, and S. Goto, "Adsorption, translocation and metabolism of arsenic fungicides, iron methanearsonate and ammonium iron methanearsonate, in rice plants," Journal of Pest Science, vol. 12, pp. 199-208, 1987.

[21] A. A. Benson, R. V. Cooney, and J. M. Herrera-Lasso, "Arsenic metabolism in algae and higher plants," Journal of Plant Nutrition, vol. 3, no. 1-4, pp. 285-292, 2008.
[22] P. Nissen and A. A. Benson, "Arsenic metabolism in fresh-water and terrestrial plants," Physiologia Plantarum, vol. 54, no. 4, pp. 446-450, 1982.

[23] WHO (World Health Organization), "Exposure to arsenic: a major public health concern," 2010, http://www.who.int/ipcs/ features/arsenic.pdf?ua=1.

[24] WHO (World Health Organization), "Arsenic in drinkingwater. Background document for preparation of WHO Guidelines for drinking-water quality," 2011, http://www.who.int/ water_sanitation_health/dwq/chemicals/arsenic.pdf.

[25] Council Directive 98/83/EC, OJ. L330/32-L330/53, 1998, https:// www.fsai.ie/uploadedFiles/Legislation/Food_Legisation_Links/ Water/EU_Directive_98_83_EC.pdf.

[26] EFSA (European Food Safety Authority) Panel on Contaminants in the Food Chain, "Scientific opinion on arsenic in food," EFSA Journal, vol. 7, no. 10, article 1351, 2009.

[27] US Food and Drug Administration (US FDA), "Arsenic in rice and rice products," 2014, http://www.fda.gov/Food/FoodborneIllnessContaminants/Metals/ucm319948.htm.

[28] Food and Agriculture Organization/World Health Organization (JECFA), "Joint FAO/WHO Food Standards Committee of the Codex Alimentarius," 2014, http://www.fao.org/news/story/ pt/item/238558/icode/.

[29] P. N. Williams, A. H. Price, A. Raab, S. A. Hossain, J. Feldmann, and A. A. Meharg, "Variation in arsenic speciation and concentration in paddy rice related to dietary exposure," Environmental Science and Technology, vol. 39, no. 15, pp. 5531-5540, 2005.

[30] J. M. Duxbury, A. B. Mayer, J. G. Lauren, and N. Hassan, "Food chain aspects of arsenic contamination in Bangladesh: effects on quality and productivity of rice," Journal of Environmental Science and Health, vol. 38, no. 1, pp. 61-69, 2003.

[31] S. Caroli, C. Frazzoli, M. D’Amato, and Gy. Záray, "Arsenic and other potentially toxic trace elements in rice," in The Determination of Chemical Elements in Food: Applications for Atomic and Mass Spectrometry, S. Caroli, Ed., John Wiley \& Sons, Rome, Italy, 2007.

[32] S. D’Ilio, M. Alessandrelli, R. Cresti, G. Forte, and S. Caroli, "Arsenic content of various types of rice as determined by plasma-based techniques," Microchemical Journal, vol. 73, no. 12, pp. 195-201, 2002.

[33] I. Pizarro and M. Gómez, "Evaluation of stability of arsenic species in rice," Analytical and Bioanalytical Chemistry, vol. 376, no. 1, pp. 102-109, 2003.

[34] A. Gonzálvez, A. Llorens, M. L. Cervera, S. Armenta, and M. de la Guardia, "Non-chromatographic speciation of inorganic arsenic in mushrooms by hydride generation atomic fluorescence spectrometry," Food Chemistry, vol. 115, no. 1, pp. 360364, 2009.

[35] H. Wu, X. Wang, B. Liu et al., "Simultaneous speciation of inorganic arsenic and antimony in water samples by hydride generation-double channel atomic fluorescence spectrometry with on-line solid-phase extraction using single-walled carbon nanotubes micro-column," Spectrochimica Acta Part B: Atomic Spectroscopy, vol. 66, no. 1, pp. 74-80, 2011.

[36] G. Yang, L. Ma, D. Xu et al., "Levels and speciation of arsenic in the atmosphere in Beijing, China," Chemosphere, vol. 87, no. 8, pp. 845-850, 2012.

[37] H. Naranmandura, N. Bu, K. T. Suzuki, Y. Lou, and Y. Ogra, "Distribution and speciation of arsenic after intravenous administration of monomethylmonothioarsonic acid in rats," Chemosphere, vol. 81, no. 2, pp. 206-213, 2010. 
[38] N. Campillo, R. Peñalver, P. Viñas, I. López-García, and M. Hernández-Córdoba, "Speciation of arsenic using capillary gas chromatography with atomic emission detection," Talanta, vol. 77, no. 2, pp. 793-799, 2008.

[39] G. Yang, J. Xu, J. Zheng et al., "Speciation analysis of arsenic in Mya arenaria Linnaeus and Shrimp with capillary electrophoresis-inductively coupled plasma mass spectrometry," Talanta, vol. 78, pp. 471-476, 2009.

[40] H. Matusiewicz and M. Ślachciński, "Development of a new hybrid technique for inorganic arsenic speciation analysis by microchip capillary electrophoresis coupled with hydride generation microwave induced plasma spectrometry," Microchemical Journal, vol. 102, pp. 61-67, 2012.

[41] M. N. M. Reyes, M. L. Cervera, R. C. Campos, and M. de la Guardia, "Non-chromatographic speciation of toxic arsenic in vegetables by hydride generation-atomic fluorescence spectrometry after ultrasound-assisted extraction," Talanta, vol. 75, no. 3, pp. 811-816, 2008

[42] M. Welna, A. Szymczycha-Madeja, and P. Pohl, "Comparison of strategies for sample preparation prior to spectrometric measurements for determination and speciation of arsenic in rice," TrAC-Trends in Analytical Chemistry, vol. 65, pp. 122136, 2015.

[43] H. C. Rezende, I. L. S. Almeida, L. M. Coelho, N. M. M. Coelho, and T. L. Marques, "Non-chromatographic methods focused on speciation of arsenic and selenium in food and environmental samples," Sample Preparation, vol. 2, pp. 31-48, 2014.

[44] S. Dwivedi, A. Mishra, P. Tripathi et al., "Arsenic affects essential and non-essential amino acids differentially in rice grains: inadequacy of amino acids in rice based diet," Environment International, vol. 46, pp. 16-22, 2012.

[45] Á. A. Carbonell-Barrachina, X. Wu, A. Ramírez-Gandolfo et al., "Inorganic arsenic contents in rice-based infant foods from Spain, UK, China and USA," Environmental Pollution, vol. 163, pp. 77-83, 2012.

[46] G. Raber, N. Stock, P. Hanel, M. Murko, J. Navratilova, and K. A. Francesconi, "An improved HPLC-ICPMS method for determining inorganic arsenic in food: application to rice, wheat and tuna fish," Food Chemistry, vol. 134, no. 1, pp. 524$532,2012$.

[47] J. D. Brockman and J. W. N. Brown IV, "Measurement of arsenic species in infant rice cereals by liquid chromatography inductively coupled plasma mass spectrometry," American Journal of Analytical Chemistry, vol. 3, no. 10, pp. 693-697, 2012.

[48] A. Sommella, C. Deacon, G. Norton, M. Pigna, A. Violante, and A. A. Meharg, "Total arsenic, inorganic arsenic, and other elements concentrations in Italian rice grain varies with origin and type," Environmental Pollution, vol. 181, pp. 38-43, 2013.

[49] I. N. Pasias, N. S. Thomaidis, and E. A. Piperaki, "Determination of total arsenic, total inorganic arsenic and inorganic arsenic species in rice and rice flour by electrothermal atomic absorption spectrometry," Microchemical Journal, vol. 108, pp. 1-6, 2013.

[50] K. Phan, S. Sthiannopkao, S. Heng et al., "Arsenic contamination in the food chain and its risk assessment of populations residing in the Mekong River basin of Cambodia," Journal of Hazardous Materials, vol. 262, pp. 1064-1071, 2013.

[51] B. E. S. Costa, N. M. M. Coelho, and L. M. Coelho, "Determination of arsenic species in rice samples using CPE and ETAAS," Food Chemistry, vol. 178, pp. 89-95, 2015.
[52] A. M. Shraim, "Rice is a potential dietary source of not only arsenic but also other toxic elements like lead and chromium," Arabian Journal of Chemistry, 2014.

[53] S. C. Sofuoglu, H. Güzelkaya, Ö. Akgül, P. Kavcar, F. Kurucaovali, and A. Sofuoglu, "Speciated arsenic concentrations, exposure, and associated health risks for rice and bulgur," Food and Chemical Toxicology, vol. 64, pp. 184-191, 2014.

[54] W. Jiang, Q. Hou, Z. Yang et al., "Evaluation of potential effects of soil available phosphorus on soil arsenic availability and paddy rice inorganic arsenic content," Environmental Pollution, vol. 188, pp. 159-165, 2014.

[55] G. Chen and T. Chen, "SPE speciation of inorganic arsenic in rice followed by hydride-generation atomic fluorescence spectrometric quantification," Talanta, vol. 119, pp. 202-206, 2014.

[56] M.-K. Paik, M.-J. Kim, W.-I. Kim et al., "Determination of arsenic species in polished rice using a methanol-water digestion method," Journal of the Korean Society for Applied Biological Chemistry, vol. 53, no. 5, pp. 634-638, 2010.

[57] M.-Z. Zheng, C. Cai, Y. Hu et al., "Spatial distribution of arsenic and temporal variation of its concentration in rice," New Phytologist, vol. 189, no. 1, pp. 200-209, 2011.

[58] G.-X. Sun, T. Van De Wiele, P. Alava, F. Tack, and G. Du Laing, "Arsenic in cooked rice: effect of chemical, enzymatic and microbial processes on bioaccessibility and speciation in the human gastrointestinal tract," Environmental Pollution, vol. 162, pp. 241-246, 2012.

[59] J.-Y. Kim, W.-I. Kim, A. Kunhikrishnan et al., "Determination of arsenic species in rice grains using HPLC-ICP-MS," Food Science and Biotechnology, vol. 22, no. 6, pp. 1509-1513, 2013.

[60] W. Maher, S. Foster, F. Krikowa, E. Donner, and E. Lombi, "Measurement of inorganic arsenic species in rice after nitric acid extraction by HPLC-ICPMS: verification using XANES," Environmental Science and Technology, vol. 47, no. 11, pp. 58215827, 2013.

[61] G.-X. Sun, P. N. Williams, Y.-G. Zhu et al., "Survey of arsenic and its speciation in rice products such as breakfast cereals, rice crackers and Japanese rice condiments," Environment International, vol. 35, no. 3, pp. 473-475, 2009.

[62] E. Sanz, R. Muñoz-Olivas, C. Cámara, M. K. Sengupta, and S. Ahamed, "Arsenic speciation in rice, straw, soil, hair and nails samples from the arsenic-affected areas of Middle and Lower Ganga plain," Journal of Environmental Science and Health Part A: Toxic/Hazardous Substances and Environmental Engineering, vol. 42, no. 12, pp. 1695-1705, 2007.

[63] E. Sanz, R. Muñoz-Olivas, and C. Cámara, "A rapid and novel alternative to conventional sample treatment for arsenic speciation in rice using enzymatic ultrasonic probe," Analytica Chimica Acta, vol. 535, no. 1-2, pp. 227-235, 2005.

[64] A. A. Meharg and M. M. Rahman, "Arsenic contamination of Bangladesh paddy field soils: implications for rice contribution to arsenic consumption," Environmental Science and Technology, vol. 37, no. 2, pp. 229-234, 2003.

[65] C. Cerveira, D. Pozebon, D. P. de Moraes, and J. C. S. de Fraga, "Speciation of inorganic arsenic in rice using hydride generation atomic absorption spectrometry (HG-AAS)," Analytical Methods, vol. 7, no. 11, pp. 4528-4534, 2015.

[66] R. Gürkan, U. Kır, and N. Altunay, "Development of a simple, sensitive and inexpensive ion-pairing cloud point extraction approach for the determination of trace inorganic arsenic species in spring water, beverage and rice samples by UV-Vis spectrophotometry," Food Chemistry, vol. 180, pp. 32-41, 2015. 
[67] I. López-García, M. Briceño, and M. Hernández-Córdoba, "Non-chromatographic screening procedure for arsenic speciation analysis in fish-based baby foods by using electrothermal atomic absorption spectrometry," Analytica Chimica Acta, vol. 699, no. 1, pp. 11-17, 2011.

[68] J. R. Encinar, R. Ruzik, W. Buchmann, J. Tortajada, R. Lobinski, and J. Szpunar, "Detection of selenocompounds in a tryptic digest of yeast selenoprotein by MALDI time-of-flight MS prior to their structural analysis by electrospray ionization triple quadrupole MS," Analyst, vol. 128, no. 3, pp. 220-224, 2003.

[69] Z. Lin, M. Zhao, S. Zhang, C. Yang, and X. Zhang, "In situ arsenic speciation on solid surfaces by desorption electrospray ionization tandem mass spectrometry," Analyst, vol. 135, no. 6, pp. 1268-1275, 2010.

[70] T. Bacquart, G. Devès, and R. Ortega, "Direct speciation analysis of arsenic in sub-cellular compartments using micro-X-ray absorption spectroscopy," Environmental Research, vol. 110, no. 5, pp. 413-416, 2010.

[71] R. Ortega, "Direct speciation analysis of inorganic elements in single cells using X-ray absorption spectroscopy," Journal of Analytical Atomic Spectrometry, vol. 26, no. 1, pp. 23-28, 2011.

[72] A. Gonzalvez, M. L. Cervera, S. Armenta, and M. de la Guardia, "A review of non-chromatographic methods for speciation analysis," Analytica Chimica Acta, vol. 636, no. 2, pp. 129-157, 2009.

[73] B. Manning, "Arsenic speciation in As(III)- and As(V)-treated soil using XANES spectroscopy," Microchimica Acta, vol. 151, no. 3-4, pp. 181-188, 2005.

[74] D. Eveborn, J. P. Gustafsson, D. Hesterberg, and S. Hillier, "XANES speciation of $\mathrm{P}$ in environmental samples: an assessment of filter media for on-site wastewater treatment," Environmental Science and Technology, vol. 43, no. 17, pp. 6515-6521, 2009. 

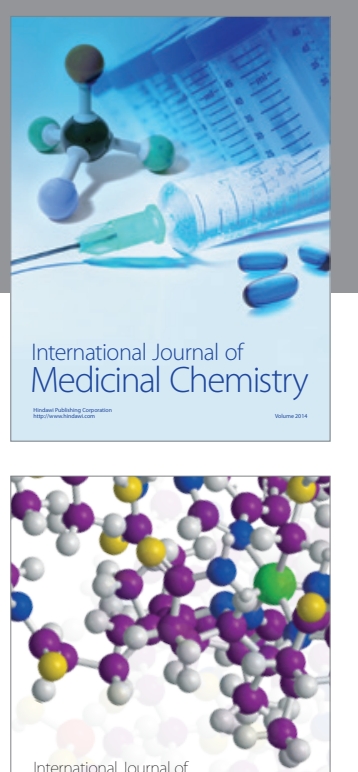

Carbohydrate Chemistry

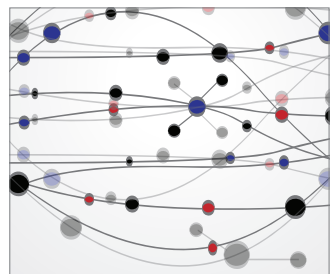

The Scientific World Journal
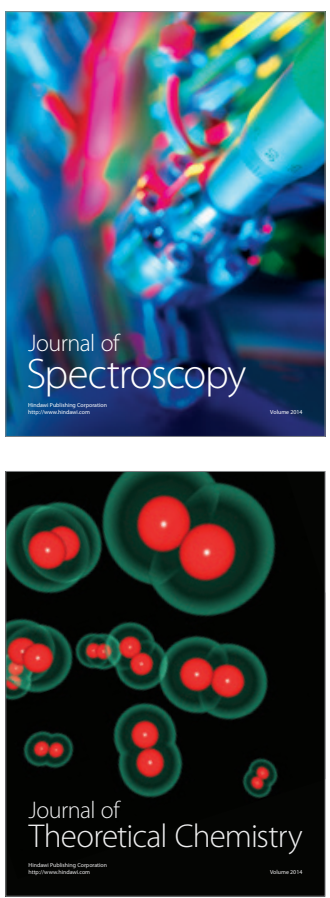
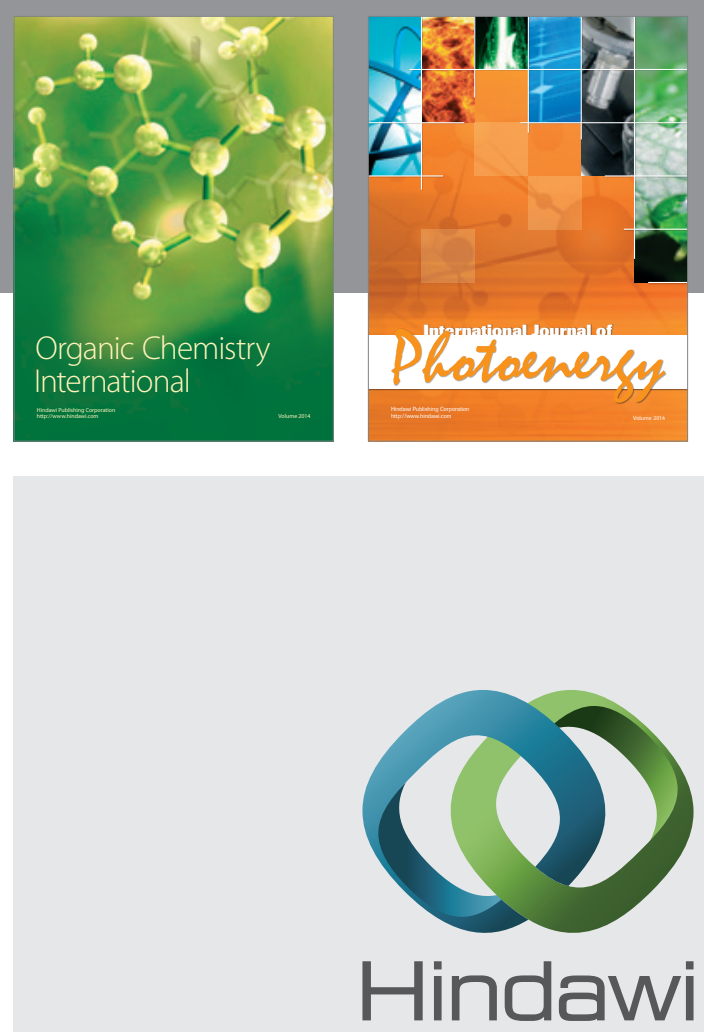

Submit your manuscripts at

http://www.hindawi.com

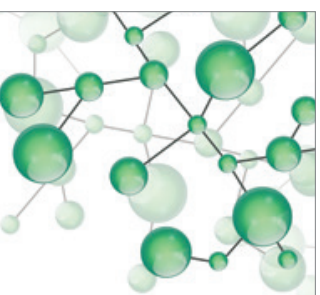

International Journal of

Inorganic Chemistry

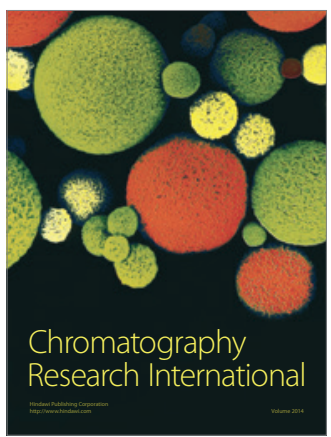

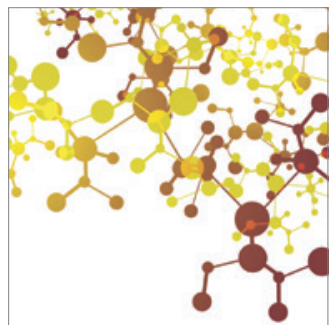

Applied Chemistry
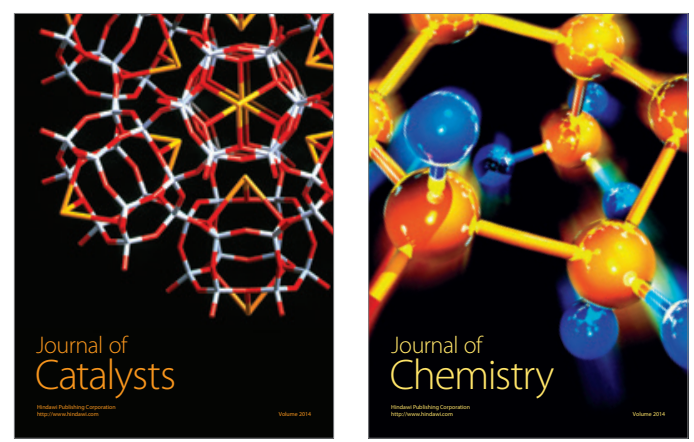
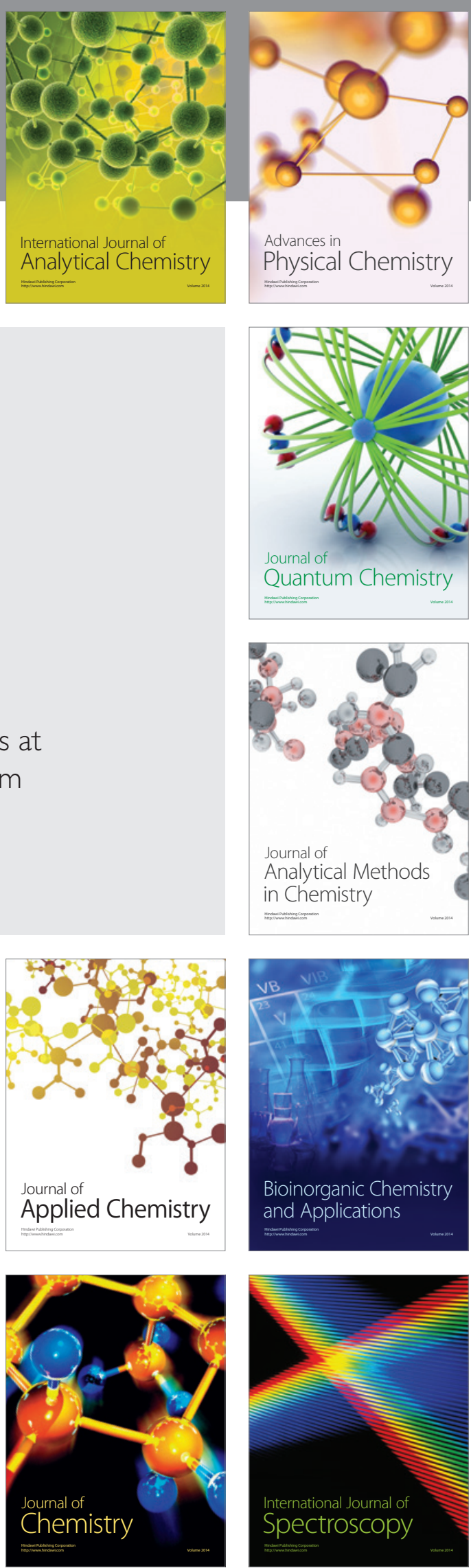